\title{
The third year of the Brazilian Journal of Geology and its international challenge
}

In October 2015, at the Symposium on the Southeastern Brazilian Geology of the Brazilian Geological Society (Sociedade Brasileira de Geologia, SBG), there was an important meeting of its Editorial Council, with the presence of 10 of its Brazilian members. The main objective of this meeting was to evaluate the situation of the journal, rethink its future, and guide its next steps toward its full internationalization.

In early 2012, Revista Brasileira de Geociências (RBG), with a four-decade-long tradition in Brazilian geology, was placed by the SBG Board of Directors under the responsibility of the present Editorial Council. With the creation of this council, the SBG wanted that the journal would take over the position of a leading national scientific channel in the area of the Earth Sciences and that it would try to improve its importance in the world geological community. After a few months of transition, the formal actions of the new board of the magazine began in July. Still as the RBG, two issues were published in September and December 2012, maintaining the punctuality that had already been acquired by the previous editorial board, whose editor-in-chief was our colleague and friend Alberto Pio Fiori. At the end of 2012, the RBG also published a complementary thematic issue: Avanços em Geologia Sedimentar, Ambiental e Hidrogeologia no Brasil. Back then, the initial goals of the RBG were to manage being accepted in international databases and also to obtain a better ranking in the QUALIS system for classification of scientific journals in the national system of the CAPES, a sector of the Ministry of Education.

With Volume 43(1) of March 2013, the RBG changed its name to Brazilian Journal of Geology (BJG), so that with its present volume, of December 2015, the BJG completes its third year of life. Eleven issues of the BJG have already been published on time, with what is best about geology in Brazil, and this is the twelfth one. Not long ago another thematic supplement was published, containing several contributions that were offered during the VI Latin American Congress of Sedimentology. I understand that the initial goals, envisioned three years ago, were obtained. The BJG was accepted by SciELO, the internationally known Brazilian scientific database, and also by the Web of Science, the main international quantometric system. The journal will receive its first impact factor in mid-2016. In addition to that, the BJG was also promoted to B1 in the classification of scientific journals compiled by the CAPES, which corresponds to the journals of international stature.

The Brazilian geological community had adapted to the new conditions offered by the BJG, and responded well to its present characteristics. The flow of submissions within the past three years is summarized in Table 1.

The table indicates that, within these three years of life, the flow of manuscripts presented some fluctuations, roughly between 6 and 10 monthly submissions. Considering the progresses made, especially on the new improved classification granted by the CAPES, it is possible to expect, in the near future, that this flow will become more pronounced. At the time, 30 articles are under evaluation.

As for the evaluation process, the migration of the editorial system OJS (Open Journals System) into ScholarOne allowed that the actions of associated editors, both Brazilian and foreign ones, would be closer to authors and reviewers, bringing about some progress in communication between them. Some associate editors are still adapting to the new system. On the other hand, the system allows faster performance and deadline control. Moreover, the editors can be chosen from any part of the world, which ensures critical reviews and international interest, allowing a considerable improvement of the content of each submission.

For the articles published between September 2012 and September 2015, the two graphs (Figures 1 and 2) show the period necessary for the evaluation process, i.e., the time spent between submission and acceptance. It is clear that this time interval depends on, besides the intrinsic quality of each article, the readiness of editors, reviewers, and authors. In both diagrams, on the axis of ordinates there is the number of days. The volumes published are represented by rectangular box plots, which include $50 \%$ of the sample population. The extremes are marked, as well as the median and the mean, in each 
Table 1. Brazilian Journal of Geology - Submission flow (2013-2015).

\begin{tabular}{l|c|c|c|c}
\hline & $\mathbf{2 0 1 3}$ & $\mathbf{2 0 1 4}$ & $\begin{array}{c}\mathbf{2 0 1 5} \\
\text { (until July) }\end{array}$ & $\begin{array}{c}\text { Total } \\
\text { (30 months) }\end{array}$ \\
\hline Articles submmited & 89 & 66 & 63 & 218 \\
\hline Articles accepted for publication & 43 & 42 & 28 & 113 \\
\hline Articles out of the scope of the Brazilian Journal of Geology & 17 & 11 & 8 & 36 \\
\hline Articles archieved or rejected in the evaluation & 13 & 21 & 5 & 39 \\
\hline Article under evaluation in October 2015 & \multicolumn{2}{|c|}{12 (Open Journal Systems) + 18 (ScholarOne) } \\
\hline
\end{tabular}

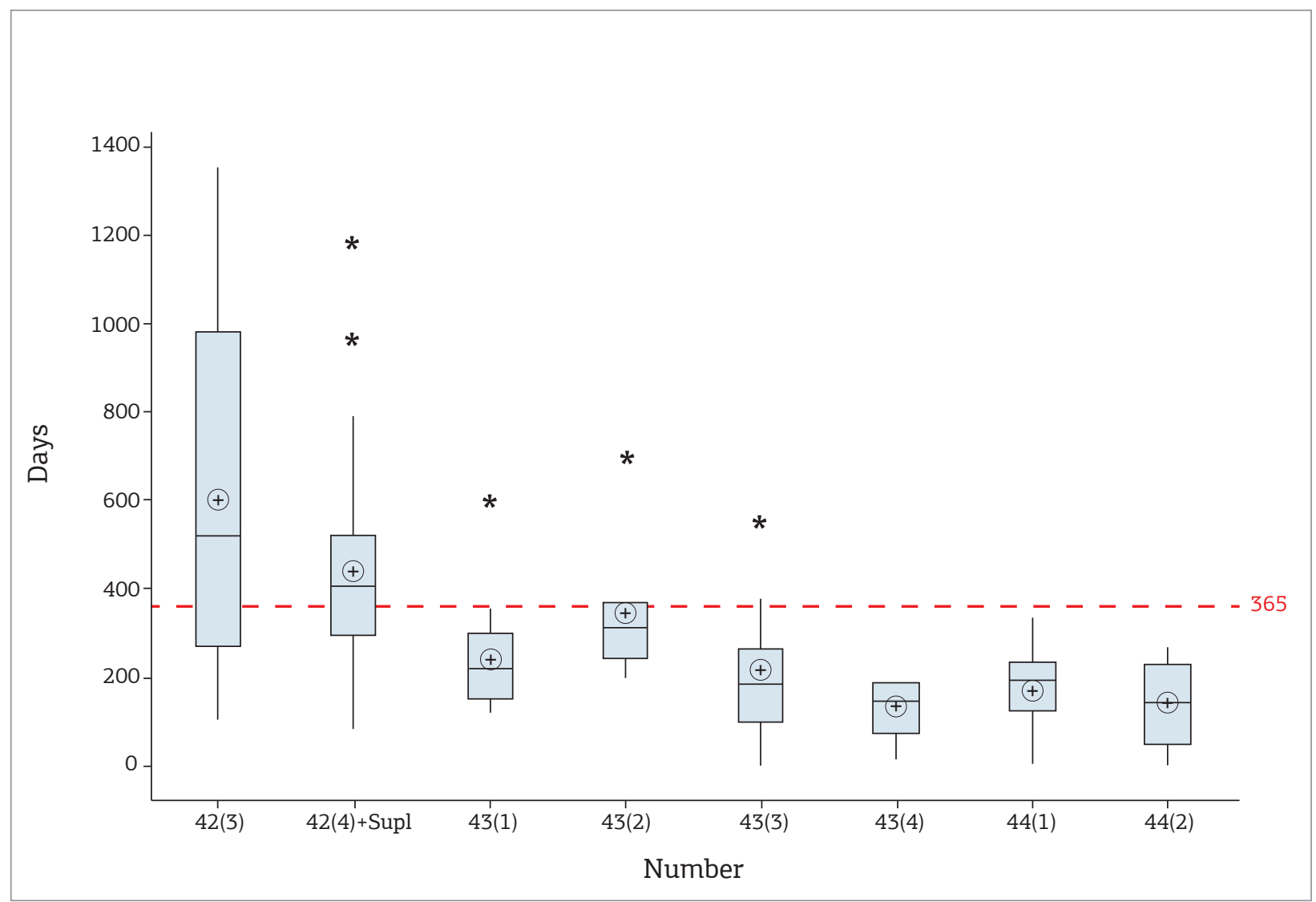

Figure 1. Time of evaluation for articles published in the Brazilian Journal of Geology. Box plots for the period between Volume 42(3), September 2012, and Volume 44(2), June 2014.

of the diagrams. The dotted line represents one year (365 days). In Figure 1, the five first box plots still include articles that were under evaluation for a long time, indicated as outliers with an asterisk in the diagram, some of them with over three years. From the fourth issue published in 2013 on, the period for the evaluations was kept, on average, close to six months. Figure 2, with an expanded vertical scale, shows that all articles published in 2014 and 2015 were evaluated in less than one year, and it seems that the evaluation process is actually improving with time. In the last three issues, the mean evaluation period resulted around four months, consistent with that of similar international journals.

The flow of manuscripts and the mean period of the evaluation process indicate that at present the journal has a relatively stable editorial regime. However, Figure 3, showing the evolution of the number of daily downloads of the BJG articles, since September 2012 until September 2015, brings a sign of alert. Before July 2013, the number of downloads was always low, but in the second semester of this year it reached an average of 7-8 daily downloads, with some peaks of 30 downloads. 


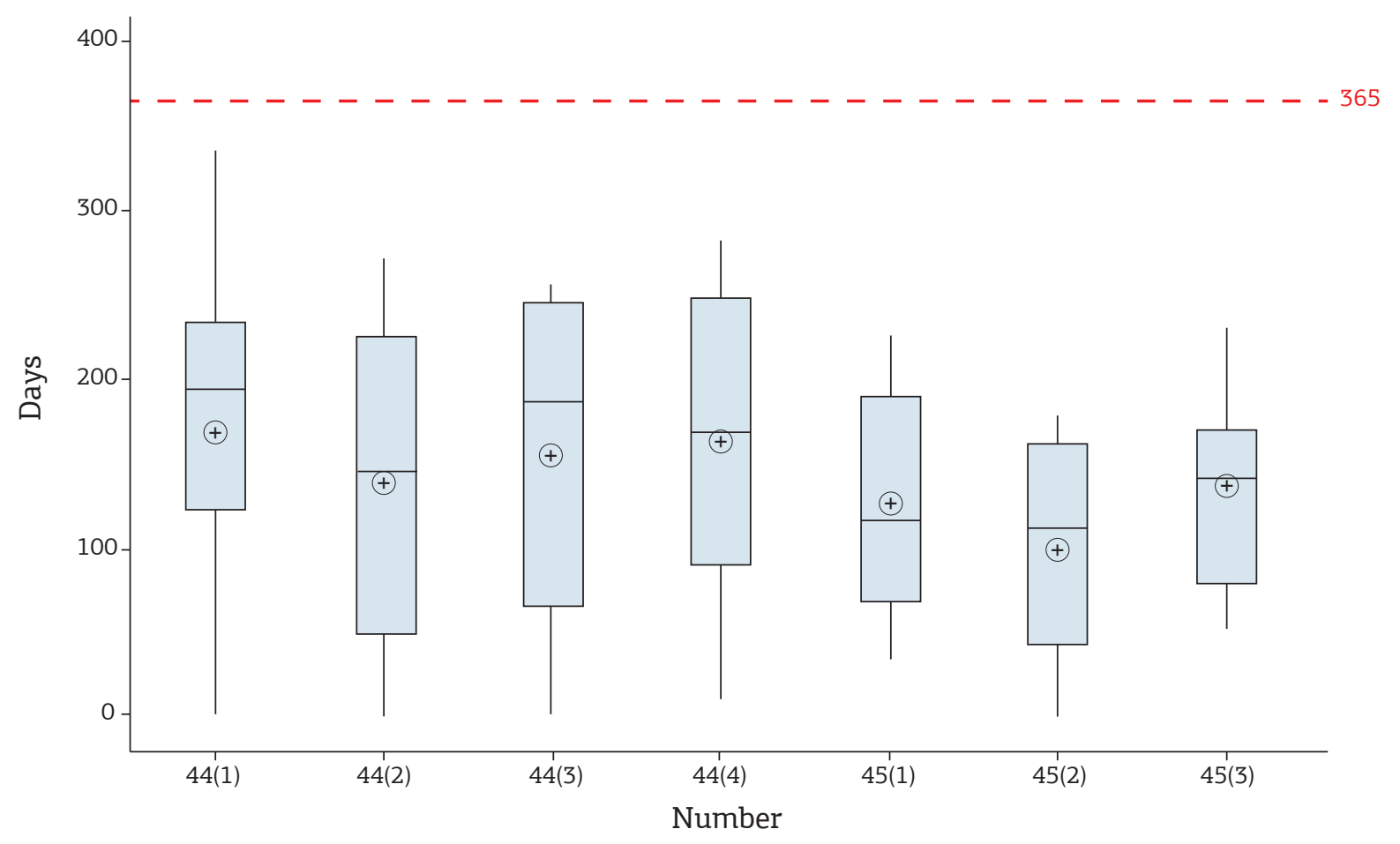

Figure 2. Time of evaluation for articles published in the Brazilian Journal of Geology. Box plot for the period between Volume 44(1), March 2014, and Volume 45(3), September 2015.

There was some decrease from then on, and the daily mean is currently about 4 and 5 downloads, with some peaks of 20 . What would the cause of this decrease be? As I see it, the journal should seek its international insertion with a better content, regarding international interest. This will also bring a higher impact factor. Currently, still on hold for 2016 and for its first impact factor by Thomson Reuters, the situation of the BJG in Scimago was already indicated for 2013 and 2014 . In the ranking of 40 Latin American journals within the Exact and Earth Sciences, the BJG went from 27th in 2013 (SJC=0.14) to 14 th in 2014 (SJG=0.22). I believe that we can still improve. The best ranked Latin American geological journal, at the moment, is the Chilean Andean Geology, with SJC close to 0.8 in 2014.

In the recent meeting of the BJG Editorial Council, there was some discussion regarding the future of our publication. There was a consensus that, in order to proceed with the internationalization, it will be important that the articles to be published, although maintaining its regional character, could bring elements of evident potential international interest. The members of the council themselves declared their willingness to contribute, in the future, with articles of their own, or of their students. Besides that, an essential decision was made: from 2016 on, the BJG submissions must be only in English. Another important decision was to change the "Instructions to authors" so that they would be best suited to the editorial system ScholarOne. The new instructions may be found at the end of this issue and also in the websites of SciELO and SBG. They were inspired in international journals with tradition in the Geosciences (Elsevier), and certainly they will guide the preparations of submissions with greater outreach and international appeal.

The path of the BJG is determined. The Brazilian geological community has already earned the respect of the world by its maturity and its great expertise in several fields of the Earth Sciences. In the international publications of the area, there are many excellent contributions of Brazilian authors, and it is important and necessary that this would go on. What we go for with the BJG is to have a greater number of Brazilian authors in the international scenario. Moreover, the internationalization process involves a learning that stimulates the search of breakthroughs at the frontier of the science instead of research with predominantly local focus. In the conception of their own work, Brazilian authors may choose titles for their 
40

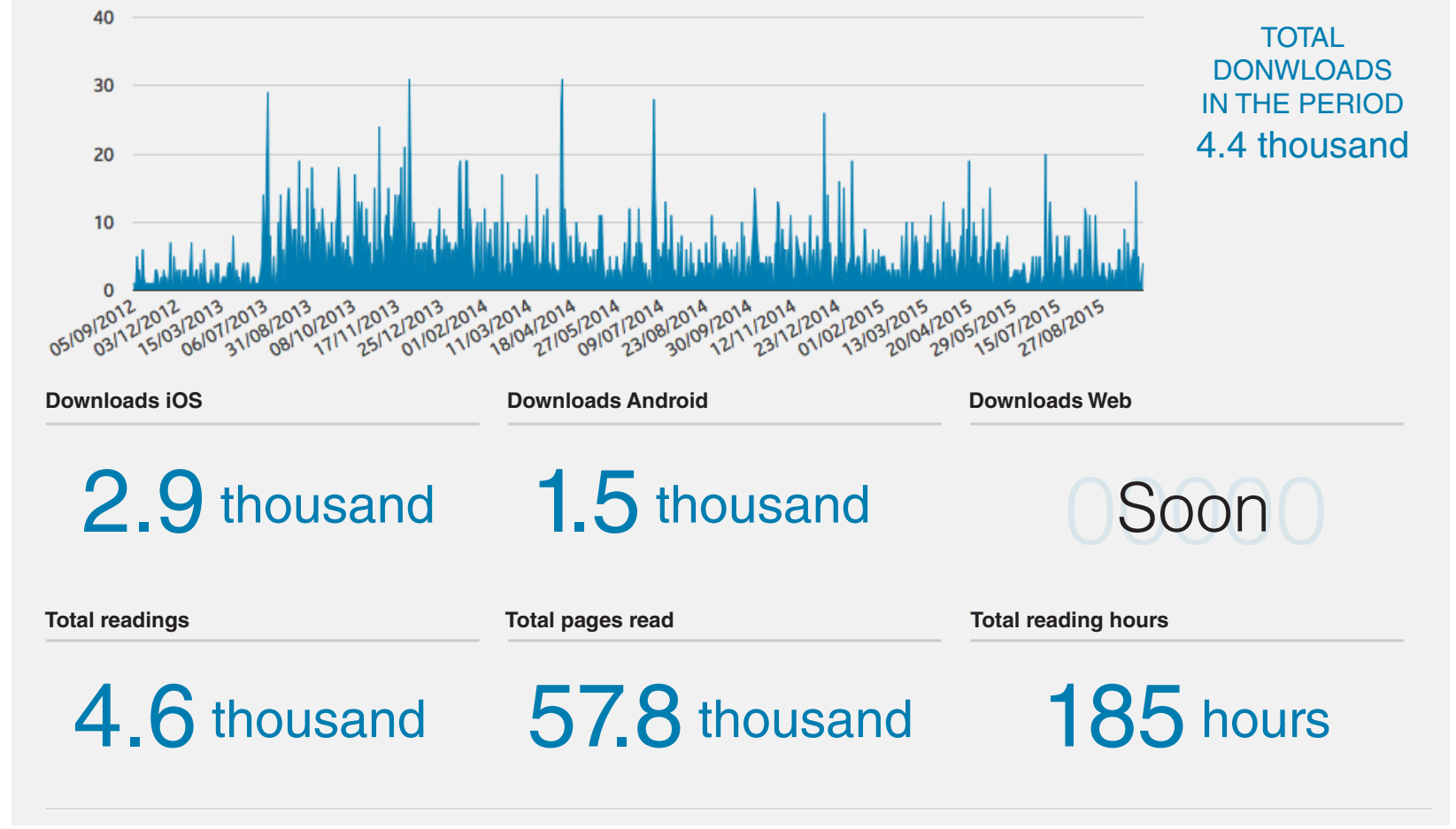

Figure 3. Brazilian Journal of Geology. Report of downloads from September 2012 to August 2015.

articles related to solutions of problems with broad nature, and also the preparation of abstracts more informative and more appealing for an international audience. As I see it, this could be done immediately and will count on proactive actions of the editorial council of the BJG.

Due to some editorial reasons, and also because the journal shall not lose its punctuality, this Volume 45(4) will be available on the websites of the journal and SciELO well before the end of December, and therefore it brings only seven articles, less than its normal average number. I believe in a very satisfactory future for our journal in the international scenario, and I am sure that our Brazilian geological colleagues, both academics and professionals, will go on collaborating with the journal and will continue to submit their best contributions to the BJG.

Umberto G. Cordani Editor-in-chief 